\title{
Effect of uterine fibroids anatomical locations in marriage Sudanese women
}

\author{
Mohammed A. A. Abdelmtalab, Tahir Osman Ali, Khalid Hussein Bakheit Ahmed, \\ Hamza Mohammed Ali Idriss
}

\author{
Corresponding author: Dr. Mohammed A.A. Abdelmtalab, Assistant Professor. Anatomy \\ Department, Faculty of Medicine, International University of Africa, Sudan; \\ Email : salam_ahamed@yahoo.com
}

Distributed under Attribution-Non Commercial - Share Alike 4.0 International (CC BY-NC-SA 4.0)

\begin{abstract}
Background: Uterine fibroids are most common gynecological tumor in women of reproductive age. However, its symptoms were affecting the women quality of life. Aims: The goal of this study is to investigate the impact of uterine anatomical locations in marriage Sudanese women at Omdurman Maternity Hospital between 2014-2105. Methods: The study included 126 confirmed cases of uterine fibroids investigated at the hospital clinically and ultrasonographically. Result: Most of our population were symptomatic fibroids representing $73.8 \%$. The highest incidence was observed among the age group of $(36-40)$ years. However the university level $(39.7 \%)$, house wife $(70.6 \%)$ and highest economical level $(3.2 \%)$ were the least one. Most common anatomical locations of uterine fibroids were intramural $(34.9 \%)$, intramural-intramural $(15.1 \%)$ and intramural-subserosal $(21.4 \%)$. Menorrhagia $(33.3 \%)$, abdominal mass $(27.0 \%)$, dysmenorrhagia $(23.8 \%)$ and menstrual problems $(23.0 \%)$ were the commonest presentations. There were association between the infertility, menstrual problem and ovarian cyst with anatomical locations of uterine fibroids. Conclusion: The present study revealed that single intramural uterine fibroids are the most common type which produces fibroid symptoms; menorrhagia was the commonest clinical presentation.
\end{abstract}

Keywords: Anatomical locations, fibroids, marriage women.

With Uterine fibroids are the most frequent benign gynecologic tumors, affecting 70 to $80 \%$ of women. ${ }^{1}$ Uterine fibroid is a common concern in women at fertile age, causing multiple symptoms which may have a negative impact on different aspects of women's life and cause considerable morbidity. ${ }^{2,3}$ Uterine fibroids are the leading cause for hysterectomy, and costs exceed 34 billion dollars annually in the United States. ${ }^{4}$ Black race, heredity, nulliparity, obesity, polycystic ovary syndrome, vitamin D deficiency, early life, environmental exposure to toxins, lifestyle, infection, diabetes and hypertension are associated with increased risk of fibroids. ${ }^{5,6}$ The incidence of fibroids in black women is three times greater than that in white women. The ethnic and genetic predisposition and ovarian hormone exposure are the main determinants of a fibroid development. ${ }^{7-9}$ Fibroids are associated with abnormal uterine bleeding with longer, heavier menstrual cycles, fatigability, pelvic pressure, enlarged uterus that presses on the bladder and induce pelvic pain and frequent urination. ${ }^{10}$ The relationship between fibroids and infertility is not clearly understood. It was thought that submucosal, intramural and subserosal fibroids interfere with reproductive capacity. Miscarriage rates after myomectomy appear to be reduced. ${ }^{11}$ Most of fibroids do not show any significant change in their volume during pregnancy. ${ }^{12}$ Pradhan et al (2006) studied 137 cases of uterine fibroids that represented $38.5 \%$ of all abdominal hysterectomies performed during the same period. They reported the presenting symptoms as follows; menstrual bleeding (73.0\%), abdominal mass and pain (58.4\%), dysmenorrhea (18.2\%) and infertility $(7.3 \%)$ as the common

Received: $27^{\text {th }}$ July 2020, Peer review completed: $15^{\text {th }}$ September 2020, Accepted: $\mathbf{1}^{\text {st }}$ October 2020.

Abdelmtalab MAA, Osman Ali T, Hussein Bakheit Ahmed K, Mohammed Ali Idriss H. Effect of uterine fibroids anatomical locations in marriage Sudanese women. The New Indian Journal of OBGYN. 2021; 8(1): 46-51. 
The New Indian Journal of OBGYN. 2021 (July-December);8(1)

symptoms. ${ }^{13}$ A large subserosal fibroid during early pregnancy caused a uterine torsion with rupture of its capsule, leading to massive intra-abdominal hemorrhage. ${ }^{14}$

It is estimated that at least $50 \%$ of fibroids are asymptomatic. However, asymptomatic fibroids may become symptomatic in the ner future. ${ }^{15} 20 \%$ of fibroids do increase in size, while a similar percentage decreases in size. ${ }^{16}$ Other pathologic conditions, including ectopic pregnancy, rupture or torsion of an ovarian cyst, or acute pelvic inflammatory disease, need to be considered in any woman with identifiable myomas. ${ }^{17}$ The majority of fibroids do not change their size during pregnancy, but one-third of them may grow in the first trimester. ${ }^{18}$

A study by Edwards et al (2007) showed that $50 \%$ of patients with uterine fibroids are symptomatic with abnormal bleeding, pressure like symptoms, abdominal pain or distension and infertility. ${ }^{19}$ Uterine fibroids may transform to secondary changes like hyaline, cystic or red degeneration, calcification and sarcomatous transformation, and imaging features in these conditions can mimic different pelvic pathologies. ${ }^{20}$ The first line of fibroids diagnoses is an ultrasound scan by transabdominal and transvaginal approach. Management of symptomatic uterine fibroids include intrauterine devices, endometrial ablation, human gonadotropine releasing hormone analogue and selective progesterone receptors modulator. ${ }^{21,22}$ Medical therapy to reduce the menorrhea includes hormonal contraceptives, nonsteroidal anti-inflammatory drugs and tranexamic acid. ${ }^{23}$ The location and number of fibroids, especially in the lower uterine segment increases the likelihood of cesarean section and malpresentation. ${ }^{24}$ This study was done to investigate the impact of uterine anatomical locations in marriage Sudanese women.

\section{Materials and methods}

This hospital based prospective study was planned to look at the effects of anatomical locations of uterine fibroids in the clinical presentation by using transabdominal ultrasound. The study was carried out at Omdurman Maternity Hospital, Omdurman, Khartoum State during the years 2014 and 2015. The study population was 126 patients. The patients were examined in the outpatient clinic at the department of gynecology to study their clinical presentations. Transabdominal ultrasound images were done to diagnose the location, size and numbers of the uterine fibroids. Power vision 6000 Toshiba Ultrasound machine, made in Japan, with a probe $(3.5 \mathrm{MHz})$ was used for the study. The study was approved by National Ribat University
Ethical Committee. All the patients signed an informed consent before participation. The data were coded, processed and transferred to a computer. The descriptive analysis was adopted. Software program SPSS version 16 was applied. Pearson Chi-Square Test for the purpose of studying possible relations of dependence. In all cases, a "P"-value $<0.05$ was considered significant. Frequency and \% were calculated for qualitative data. The results were presented in the shape of tables and figures.

\section{Results}

126 gynecological cases attending at Omdurman Maternity Hospital were confirmed to have uterine fibroid by ultrasound screening during the period from 2014-2015. Table 1 shows the age distribution data of the population.

Table1: Distribution of age and socioeconomic status among the investigated women $(\mathrm{N}=126)$

\begin{tabular}{ll}
\hline Age in years & Number (\%) \\
$20-25$ & $7(5.6)$ \\
$26-30$ & $24(19.0)$ \\
$31-35$ & $28(22.2)$ \\
$36-40$ & $33(26.2)$ \\
$41-45$ & $27(21.4)$ \\
$46-50$ & $6(4.8)$ \\
$51-55$ & $1(0.8)$ \\
\hline Educational level & $1(12.7)$ \\
Illiterate & $29(23.0)$ \\
Primary & $25(19.8)$ \\
Secondary & $6(4.8)$ \\
Intermediate & $50(39.7)$ \\
University & \\
\hline Occupation & $89(70.6)$ \\
Housewife & $3(2.4)$ \\
Student & $27(21.4)$ \\
Employee & $7(5.6)$ \\
Professional & \\
\hline Socioeconomic status & $54(42.9)$ \\
Low & $68(54.0)$ \\
Moderate & $4(3.2)$ \\
High & \\
\hline Marital status & $113(89.7)$ \\
Married & $9(7.1)$ \\
Divorce & $4(3.2)$ \\
\hline Widowed &
\end{tabular}

Table 2: The distribution of the anatomical location of the detected uterine fibroids and their classification $(\mathrm{N}=126)$.

\begin{tabular}{ll}
\hline Locations & Number (\%) \\
\hline Intramural & $44(34.9)$ \\
Subserosal & $17(13.5)$ \\
Submucosal & $3(2.4)$ \\
Pedunculated-subserosal & $3(2.4)$ \\
Inramural-inramural & $19(15.1)$ \\
Subserosal-subserosal & $4(3.2)$ \\
Intramural-subserosal & $27(21.4)$ \\
Subserosal-submucosal & $3(2.4)$ \\
Intramural-pedunculated subserosal & $2(1.6)$ \\
Intramural-submucosal & $4(3.2)$ \\
\hline Classification of fibroids & $33(26.2)$ \\
Asymptomatic & $93(73.8)$ \\
Symptomatic & \\
\hline
\end{tabular}


Table 3: The clinical presentations $(\mathrm{N}=126)$.

\begin{tabular}{lll}
\hline Clinical presentations & Yes & No \\
\hline Menorrhagia & $42(33.3)$ & $84(66.7)$ \\
Dysmenorrhagia & $30(23.8)$ & $88(69.8)$ \\
Abdominal mass & $34(27.0)$ & $92(73.0)$ \\
Menstrual problems & $29(23.0)$ & $114(90.5)$ \\
Urinary problems & $29(23.0)$ & $114(90.5)$ \\
Bowel problems & $10(7.9)$ & $116(92.1)$ \\
Pressure symptoms & $15(11.9)$ & $111(88.1)$ \\
Subfertility & $9(7.1)$ & $117(92.9)$ \\
Infertility & $9(7.1)$ & $117(92.9)$ \\
Lower limb odema & $12(9.5)$ & $114(90.5)$ \\
Pallor & $10(7.9)$ & $116(92.1)$ \\
Anemia & $6(4.8)$ & $120(95.2)$ \\
Fatigability & $16(12.7)$ & $110(87.3)$ \\
Diabetes Mellitus & $6(4.8)$ & $120(95.2)$ \\
Hypertension & $11(8.7)$ & $115(91.3)$ \\
\hline
\end{tabular}

The age of the study group ranged from 20 - 55 years (mean $\pm \mathrm{SD}=36.071 \pm 6.840$ years) with most of the cases $(26.2 \%)$ having an age of $36-40$ years. About the education status university level was in $39.7 \%$, occupation level was house wife in $70.6 \%$ and highest economic status was in $3.2 \%$ of women only.

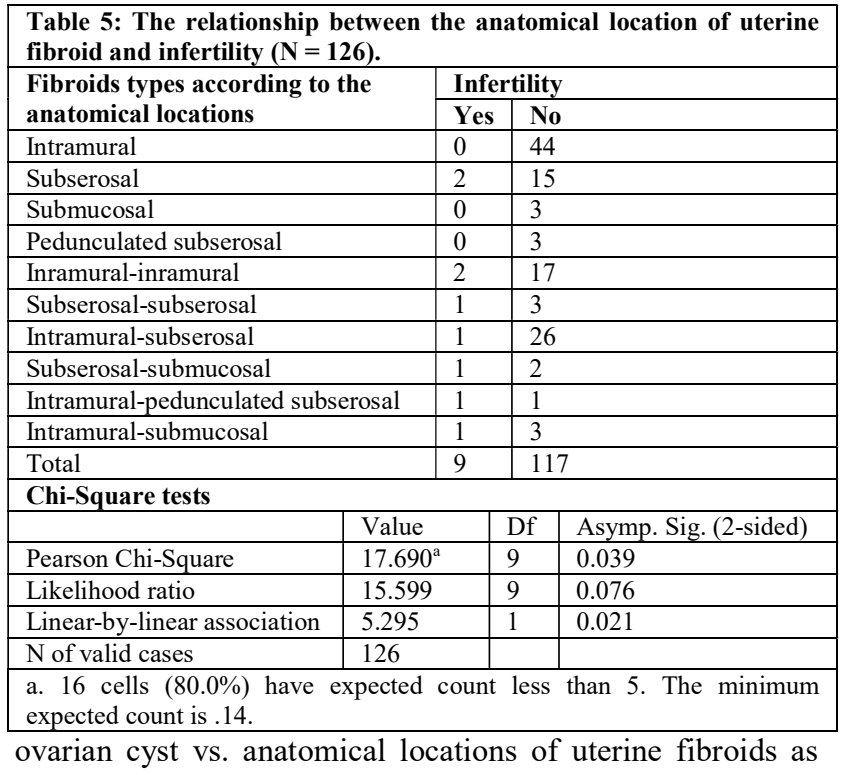

Table 4: The relationship between the anatomical location of uterine fibroid and menstrual problem $(\mathrm{N}=126)$.

\begin{tabular}{llll} 
menstrual problem $\quad(\mathbf{N}=\mathbf{1 2 6})$. & \multicolumn{2}{l}{} \\
\hline $\begin{array}{llll}\text { Fibroids types according to the } \\
\text { anatomical locations }\end{array}$ & \multicolumn{2}{l}{ Menstrual problem } & Total \\
\hline Intramural & No & \\
Subserosal & 17 & 27 & 44 \\
Submucosal & 0 & 17 & 17 \\
Pedunculated subserosal & 1 & 2 & 3 \\
Inramural-inramural & 1 & 2 & 3 \\
Subserosal-subserosal & 5 & 14 & 19 \\
Intramural-subserosal & 2 & 2 & 4 \\
Subserosal-submucosal & 1 & 26 & 27 \\
Intramural-pedunculated subserosal & 0 & 3 & 3 \\
Intramural-submucosal & 0 & 2 & 2 \\
Total & 2 & 2 & 4 \\
\hline Chi-Square tests & 29 & 97 & 126 \\
& & & \\
Pearson Chi-Square & Value & Df & Asymp. Sig. (2-sided) \\
\cline { 2 - 4 } Likelihood ratio & $22.085^{\text {a }}$ & 9 & 0.009 \\
Linear-by-linear association & 28.058 & 9 & 0.001 \\
N of valid cases & 2.892 & 1 & 0.089 \\
\hline
\end{tabular}

a. 14 cells $(70.0 \%)$ have expected count less than 5 .

The minimum expected count is .46 .

Table 2 viewed that most common anatomical locations of uterine fibroids in marriage Sudanese women were intramural $(34.9 \%)$, intramural-intramural $(15.1 \%)$ and intramural-subserosal (21.4\%). Classification of fibroid according to symptoms; symptomatic marriage women fibroids represent $73.8 \%$ and $26.2 \%$ were asymptomatic as shown in the table 2. Menorrhagia (33.3\%), abdominal mass $(27.0 \%)$ and dysmenorrhogia (23.8\%) were the commonest presentations. Menstrual and urinary problems have the same impact $(23.0 \%)$ as viewed in table 3 . There were significant relationships between the menstrual problem infertility and shown in table 4, 5 and 6.

\section{Discussion}

126 gynecological cases attending Omdurman Maternity Hospital cases were confirmed to have uterine fibroid by clinical and ultrasound screening. The highest incidence of uterine fibroid was noticed among women aging 36-40 years. We observed that the incidence of uterine fibroids increases gradually and then decreases over 50 years as shown in table 1. In comparison to another study from Nigeria it indicates that the incidence of uterine fibroid was much higher at $36-45$ years. ${ }^{25}$ Also a self-reported prevalence study of uterine fibroid from United Kingdom and Italy identify that fibroids found and confirmed that laminate are common and occur with increasing frequency with advancing age. In this study, $73.8 \%$ of patients with uterine fibroids experience symptoms, which is not in accordance with the current literature, such as the studies by Stovall $2001{ }^{26}$ who report that in symptomatic fibroids, it was estimated that only $20 \%$ to $50 \%$ of women may attribute their complaints to the fibroid itself and Cramer et al who reported that most women with uterine fibroids are asymptomatic. ${ }^{27}$

In our women, intramural and subserosal were the dominant locations which agree with finding of Medikare et al (2011) who mentioned that subserosal and intramural anatomical locations represent the majority (95\%) of all among the age group of 40-49 years. ${ }^{2}$ This enhances 
Table 6: The relationship between the anatomical location of uterine fibroid and ovarian cyst $(\mathrm{N}=126)$.

\begin{tabular}{lllll}
\hline \multirow{2}{*}{ Anatomical locations } & \multicolumn{2}{l}{ Ovarian cyst } & \multicolumn{2}{c}{ Total } \\
& No & Unilateral & Bilateral & \\
\hline Intramural & 41 & 3 & 0 & 44 \\
Subserosal & 14 & 3 & 0 & 17 \\
Submucosal & 3 & 0 & 0 & 3 \\
Pedunculated subserosal & 2 & 1 & 0 & 3 \\
Inramural-inramural & 18 & 1 & 0 & 19 \\
Subserosal-subserosal & 4 & 0 & 0 & 4 \\
Intramural-subserosal & 24 & 3 & 0 & 27 \\
Subserosal-submucosal & 3 & 0 & 0 & 3 \\
Intramural-pedunculated subserosal & 2 & 0 & 0 & 2 \\
Intramural-submucosal & 3 & 0 & 1 & 4 \\
\hline
\end{tabular}
Chi-Square tests

\section{Pearson Chi-Square}

Likelihood ratio

Linear-by-linear association

$\mathrm{N}$ of valid cases

a. 26 cells $(86.7 \%)$ have expected count less than 5 .

The minimum expected count is .02 .

uterine fibroids. ${ }^{28}$ Although another study agreeably showed that subserosal myomas have the highest incidence (54\%), their intramural location came first (34.78\%) and subserosal $(14.49 \%)$ came second as single mass. ${ }^{29}$ In this study single fibroid were in 67 women and multiple in 59 women. Reportedly, it is known that the majority of fibroids are multiple, whereas $2 \%$ only are single. ${ }^{20}$ These finding agreed with Mahmoud et al (2014) who investigated the frequency of fibroid and its presentation among the marriage Sudanese women and mentioned that $8 \%$ of fibroid cases were presented as single fibroids, while only $2.7 \%$ were multiple fibroids. $^{30}$

The high prevalence of uterine fibroids among reproductive age women with symptoms of pain and heavy bleeding affect their daily work and social activities. ${ }^{31}$ Most of our patients found in this study were house wife $(70.6 \%)$, suffering from menorrhagia, abdominal mass, dysmenorrhagia and urinary problems symptoms which were associated with morbidity.

Uterine fibroids are the source of major quality of life issues for approximately $25 \%$ of all women, who suffer from clinically significant symptoms of UL. ${ }^{32}$ Concerning the fibroid symptoms, submucosal fibroids are commonly symptomatic, intramural fibroids are mostly asymptomatic and subserosal fibroids are usually asymptomatic. ${ }^{20}$ Comparison of these findings to the current study, our intramural and subserosal fibroids were mostly symptomatic. Menorrhagia (33.3\%), abdominal mass $(27.0 \%)$, dysmenorrhagia $(23.8 \%)$ and menstrual problems $(23.0 \%)$ were the commonest presentations in our study sample.
Heavy menstrual bleeding is most common symptoms, occurs in about one-third of patients. ${ }^{33} \mathrm{~A}$ study reported that abnormal bleeding occurs in $30 \%$ of symptomatic women. ${ }^{34}$ Similar to the finding of the present study. Pradhan et al (2006) reported that menstrual bleeding (73.0\%), abdominal mass and pain (58.4\%) and dysmenorrhea (18.2\%) as the common symptoms. ${ }^{13}$ The finding of the present study has same symptoms sequences. A large subserosal fibroid during early pregnancy caused a uterine torsion with rupture of its capsule, leading to massive intraabdominal hemorrhage. ${ }^{14}$ Another study showed that the lower abdominal swelling was the commonest presenting complaint $(48.8 \%)$, followed by menorrhagia accounting for $(35.4 \%){ }^{35} \mathrm{In}$ comparison, the current study showed that Menorrhagia was the observed as the commonest presentation, followed by abdominal mass that came at a rate lower than that study mentioned. Uterine fibroids have a higher prevalence in patients with infertility. ${ }^{36}$ An increase of pregnancy loss and reduction in pregnancy and live birth rates was documented during the analysis of women with intramural uterine fibroids. ${ }^{37}$ The fibroids affect the fertility in about $7.3 \%{ }^{13}$ of women which is similar to our findings. The fibroids may be associated with infertility in about $5-10 \%$ of cases and intramural fibroids appear to decrease the fertility. ${ }^{38}$ The present study showed that the rate of fibroid-associating infertility was $7.1 \%$ that follows the same pattern as in other studies. Another study at Gazera state conducted on 200 infertile couples, found that uterine fibroids were present in 11 women (5.5\%); out of which five of them $(50 \%)$ had secondary infertility. ${ }^{39}$ Our results shows $7.1 \%$, slightly more than that. The present study revealed that infertility, menstrual problem and ovarian cyst had significant association with uterine fibroids.

Limitations of the study: The study was conducted on small sample size the future researches should maximize the study sample. There were not much cases of pregnant women with fibroids to evaluate the effect of fibroids with pregnancy.

\section{Conclusion}

Menorrhagia (33.3\%), abdominal mass (27.0\%), dysmenorrhagia (23.8\%) and menstrual problems $(23.0 \%)$ were the commonest presentations of fibroids. Intramural and subserosal were the commonest anatomical locations in marriage Sudanese women. However, more studies were 
needed to determine the impacts of anatomical location of uterine fibroid with using another method of assessment. The symptoms produced by uterine fibroids were distressing and impair the quality of life of women, thus care and treatment is very important to prevent any complications.

Acknowledgments: We express our gratitude to Maternity hospital staff, who contributed to this research.

\section{Conflict of interest: None. Disclaimer: Nil.}

\section{References}

1. Elkafas H, Qiwei Y, Al-Hendy A. Origin of uterine fibroids: conversion of myometrial stem cells to tumorinitiating cells. Semin Reprod Med. 2017; 35(6): 481-6.

2. Zimmermann A, Bernuit D, Gerlinger C, Schaefers M, Geppert K. Prevalence, symptoms and management of uterine fibroids: an international internet-based survey of 21,746 women. BMC Women Health J. 2012; 12(6); $1-11$.

3. Bulun SE. Uterine fibroids. N Engl J Med. 2013; 369(14):1344-55.

4. El Andaloussi A, Chaudhry Z, Al-Hendy A, Ismail N. Uterine Fibroids: Bridging Genomic Defects and Chronic Inflammation. Semin Reprod Med. 2017; 35(6): 494-8.

5. Okolo S. Incidence, aetiology and epidemiology of uterine fibroids. Best Pract Res Clin Obstet Gynaecol. 2008; 22(4): 571-88.

6. Yang Q, Al-Hendy A. Non-coding RNAs: an important regulatory mechanism in pathogenesis of uterine fibroids. Fertil Steril. 2018;109(5):802

7. Lethaby A, Vollenhoven B. Fibroids (uterine myomatosis, leiomyomas). BMJ Clin Evid. 2015; 2015: 0814.

8. Vercellini P, Frattaruolo MP. Uterine fibroids: from observational epidemiology to clinical management. BJOG. 2017; 124(10): 1513.

9. Al-Hendy A, Myers ER, Stewart E. Uterine fibroids: burden and unmet medical need. SeminReprod Med. 2017; 35(6): 473-80.

10. Hildreth CJ, Lynm C, Glass RM. JAMA patient page. Uterine fibroids. JAMA, .2009; 301(1):122.

11. Khaund A. Impact of fibroids on reproductive function. Best Practice \& Research Clinical Obstetrics and Gynaecology J. 2008; 22(4):749-60.
12. Wallach EE, Vlahos NF. Uterine myomas: an overview of development, clinical features, and management. Obstet Gynecol. 2004; 104(2):393-406.

13. Pradhan P, Acharya N, Kharel B, Manjin M. Uterine Myoma: A Profile of Nepalese women. N J Obstet Gynaecol. 2008; 1(2): $47-50$.

14. Morozov V, Goldstein C, Xenophon L. Leiomyoma in Early Pregnancy. The Female Patient J. 2008; 33: 36-7.

15. Divakar H. Asymptomatic Uterine Fibroids. Best Pract Res Clin Obstet Gynaecol. 2008; 22(4): 643-54.

16. Thorpe-Beestona JG, Sebireb NJ. Spontaneous expulsion of submucous fibroid after preterm labour. An International Journal of Obstetrics and Gynaecology. 2002; 109: 726-7.

17. Ouyang DW, Economy KE, Norwitz ER. Obstetric Complications of Fibroids. Obstet Gynecol Clin North Am. 2006; 33(1);153-69.

18. Lee HJ, Norwitz ER, Shaw J. Contemporary Management of Fibroids in Pregnancy. Reviews in Obstetrics \& Gynecology. 2010; 3(1): 20-7.

19. Edwards RD, Moss JG, Lumsden MA, Wu O, Murray LS, Twaddle S, et al. Symptomatic Uterine Fibroids: Is Uterine Artery Embolization Better than Surgery. Uterine-artery embolization versus surgery for symptomatic uterine fibroids. N Engl J Med. 2007; 356(4): 360-70

20. Nittala PP, Shukla R. Cystic Degeneration of Uterine Fibroid Mimicking A malignant Uterine Neoplasm on MRI. International Journal of Medicine. 2013; 1 (1); 13.

21. Ong SJ, Tang YZ, Shaida N. The role of clinical radiology in the management of uterine fibroids. $\mathrm{Br} \mathrm{J}$ Hosp Med (Lond). 2019; 80(5): C66-C9.

22. Kaganov H, Ades A. Uterine fibroids: Investigation and current management trends. Aust Fam Physician. 2016; 45(10): 722-5.

23. De La Cruz MS, Buchanan EM. Uterine fibroids: diagnosis and treatment. Am Fam Physician. 2017; 95(2):100-7.

24. Phelan JP. Myomas and Pregnancy. Obstet Gynecol Clin North Am. 1995; 22 (4): 801-5.

25. Ekpo EU, Ikamaise VC, Erim A, Nnabuchi MA. Nulliparity, Delayed Child Birth and Obesity: Potential Risk Factors for Development of Uterine Fibroid in South-South Nigeria. Journal of Association of Radiographers of Nigeria. 2009; 23: 23 - 9 . 
The New Indian Journal of OBGYN. 2021 (July-December);8(1)

26. Stovall DW. Clinical Symptomatology of Uterine Leiomyomas. Clinical Obstetrics and Gynecology. 2001; 44(2): 364-71.

27. Cramer SF, Patel A. The frequency of uterine leiomyomas. American journal of clinical pathology. 1990; 94(4): 435-8.

28. Medikare V, Kandukuri LR, Ananthapur V, Deenadayal M, Nallari P. The Genetic Bases of Uterine Fibroids; A Review. J Reprod Infertil. 2011; 12(3): 181-91.

29. Akhter N, Begum F, Begum N, Chowdhury SB, Fatema $\mathrm{N}$, Amin SA, et al. Myomectomy at the Time of Cesarean Section: A Prospective Multicentre Study. Bsmmu J. 2011; 4(2): 49.

30. Mahmoud MZ, Omer A, Adam M, Musa M, et al. Study of Uterine Fibroids Incidence in Sudan. Ultrasound in Obstetrics \& Gynecology. 2014; 44(1): 358.

31. Anissa I, Vines MS. The Association Between Selfreported Major Life Events and the Presence of Uterine Fibroids. Womens Health Issues J. 2010; 20 (4): 294-8.

32. McWilliams MM, Chennathukuzhi VM. Recent Advances in Uterine Fibroid Etiology. Semin Reprod Med. 2017; 35(2): 181-9.

33. Bartels CB, Cayton KC, Chuong FS, et al. An evidencebased approach to the medical management of fibroids: a systematic review. Clin Obstet Gynecol. 2016; 59(1): 30-52.

34. Gupta S, Jose J, Manyonda I. Clinical Presentation of Fibroids. Best Pract Res Clin Obstet Gynaecol J. 2008; 22(4): 615 - 26.
35. Mohammed A, Shehu SS, Ahmed SA, Mayun AA, Tiffin IU, Alkali G, et al. Uterine Leiomyomata: A five Year Clinicopathological Review in Zaria, Nigeria. Nigerian Journal Of surgical Research. 2005; 7(1-2): 206-8.

36. Zepiridis L, Grimbizis GF, Tarlatzis BC. Infertility and uterine fibroids. Best Pract Res Clin Obstet Gynaecol. 2016; 34: 66-73.

37. Brady PC, Stanic AK, Styer AK. Uterine fibroids and subfertility: an update on the role of myomectomy. Curr Opin Obstet Gynecol. 2013; 25(3): 255-9.

38. Bendifallah S, Brun JL, Fernandez H. Myomectomy for Infertile Momen: The Role of Surgery. J Gynecol Obstet Biol Reprod. 2011; 40(8): 885-901.

39. Osman AA. Etiology of Female Infertility in Gezera (Central Sudan). Jornal of Applied Science. 2010; 10(19): 2333-7.

\footnotetext{
Mohammed A. A. Abdelmtalab ${ }^{1}$, Tahir Osman Ali ${ }^{2}$, Khalid Hussein Bakheit Ahmed ${ }^{3}$, Hamza Mohammed Ali Idriss ${ }^{4}$

${ }^{1}$ Assistant Professor. Anatomy Department, Faculty of Medicine, International University of Africa, Sudan;

2 Professor, Anatomy Department, Faculty of Medicine, National Ribat University, Sudan; ${ }^{3}$ Associate Professor, Department of Clinical Biochemistry, King Abdulaziz University, Saudi Arabia; ${ }^{4}$ Assistant Professor, Departement of Obstetrics \& Gynecology, Faculty of Medicine, University of Kassala, Kassala, Sudan.
} 